\title{
Single-Cell Recordings to Target the Anterior Nucleus of the Thalamus in Deep Brain Stimulation for Patients with Refractory Epilepsy
}

Citation for published version (APA):

Schaper, F. L. W. V. J., Zhao, Y., Janssen, M. L. F., Wagner, G. L., Colon, A. J., Hilkman, D. M. W., Gommer, E., Vlooswijk, M. C. G., Hoogland, G., Ackermans, L., Bour, L. J., Van Wezel, R. J. A., Boon, P., Temel, Y., Heida, T., Van Kranen-Mastenbroek, V. H. J. M., \& Rouhl, R. P. W. (2019). Single-Cell Recordings to Target the Anterior Nucleus of the Thalamus in Deep Brain Stimulation for Patients with Refractory Epilepsy. International Journal of Neural Systems, 29(4), [1850012]. https://doi.org/10.1142/S0129065718500120

Document status and date:

Published: 01/05/2019

DOI:

10.1142/S0129065718500120

Document Version:

Publisher's PDF, also known as Version of record

Document license:

Taverne

Please check the document version of this publication:

- A submitted manuscript is the version of the article upon submission and before peer-review. There can be important differences between the submitted version and the official published version of record.

People interested in the research are advised to contact the author for the final version of the publication, or visit the DOI to the publisher's website.

- The final author version and the galley proof are versions of the publication after peer review.

- The final published version features the final layout of the paper including the volume, issue and page numbers.

Link to publication

\footnotetext{
General rights rights.

- You may freely distribute the URL identifying the publication in the public portal. please follow below link for the End User Agreement:

www.umlib.nl/taverne-license

Take down policy

If you believe that this document breaches copyright please contact us at:

repository@maastrichtuniversity.nl

providing details and we will investigate your claim.
}

Copyright and moral rights for the publications made accessible in the public portal are retained by the authors and/or other copyright owners and it is a condition of accessing publications that users recognise and abide by the legal requirements associated with these

- Users may download and print one copy of any publication from the public portal for the purpose of private study or research.

- You may not further distribute the material or use it for any profit-making activity or commercial gain

If the publication is distributed under the terms of Article $25 \mathrm{fa}$ of the Dutch Copyright Act, indicated by the "Taverne" license above, 
See discussions, stats, and author profiles for this publication at: https://www.researchgate.net/publication/324180666

\section{Single-Cell Recordings to Target the Anterior Nucleus of the Thalamus in Deep Brain Stimulation for Patients with Refractory Epilepsy}

Article in International Journal of Neural Systems · April 2018

DOI: $10.1142 / 50129065718500120$

\section{CITATIONS}

14

17 authors, including:

Frederic L.W.V.J. Schaper

Harvard Medical School

21 PUBLICATIONS 153 CITATIONS

SEE PROFILE

Marcus L F Janssen

Maastricht Universitair Medisch Centrum

71 PUBLICATIONS 860 CITATIONS

SEE PROFILE

Some of the authors of this publication are also working on these related projects:

VISUAL MOTION PROCESSING IN MICE View project

Clinical Neurophysiology and Movement Disorders View project
345

A. Yan Zhao

29 PUBLICATIONS 437 CITATIONS

SEE PROFILE

Louis Wagner

Kempenhaeghe

39 PUBLICATIONS 895 CITATIONS

SEE PROFILE 


\title{
Single-Cell Recordings to Target the Anterior Nucleus of the Thalamus in Deep Brain Stimulation for Patients with Refractory Epilepsy
}

\author{
Frédéric L. W. V. J. Schaper*, \\ Albert J. Colon ${ }^{\ddagger}$, Danny M. W. Hilkman ${ }^{\S}$, Erik Gommer ${ }^{\S}$, Mariëlle C. G. Vlooswijk ${ }^{* \ddagger}$, \\ Govert Hoogland ${ }^{\Uparrow, \ddagger \ddagger}$, Linda Ackermans ${ }^{\Uparrow}$, Lo J. Bour\|, Richard J. A. Van Wezel ${ }^{\dagger, * *}$,

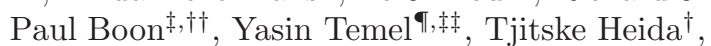 \\ Vivianne H. J. M. Van Kranen-Mastenbroek ${ }^{\ddagger, \S, \ddagger \ddagger}$ and Rob P. W. Rouhl ${ }^{*, \ddagger, \ddagger \ddagger, \S \S}$ \\ *Department of Neurology, Maastricht University Medical Center \\ Maastricht, The Netherlands \\ ${ }^{\dagger}$ Biomedial Signals and Systems Group, Department of Electrical Engineering \\ Mathematics and Computer Science, MIRA Institute for Biomedical Engineering \\ and Technical Medicine, University of Twente, Enschede, The Netherlands \\ ${ }^{\ddagger}$ Academic Center for Epileptology, Epilepsy Center Kempenhaeghe/Maastricht \\ University Medical Center, Oosterhout, Heeze and Maastricht, The Netherlands \\ $\S$ Department of Clinical Neurophysiology, Maastricht University Medical Center \\ Maastricht, The Netherlands \\ IDepartment of Neurosurgery, Maastricht University Medical Center \\ Maastricht, The Netherlands \\ "Department of Neurology and Clinical Neurophysiology \\ Academic Medical Center, University of Amsterdam \\ Amsterdam, The Netherlands \\ **Biophysics Group, Donders Institute for Brain, Cognition and Behavior \\ Radboud University Nijmegen, Nijmegen, The Netherlands \\ ${ }^{\dagger}$ Department of Neurology, University Hospital Ghent, Ghent, Belgium \\ $\ddagger_{\ddagger}$ School for Mental Health and Neuroscience (MHeNS) \\ Maastricht University, Maastricht, The Netherlands \\ $\S \S$ r.rouhl@mumc.nl
}

Accepted 16 March 2018

Published Online 16 May 2018

\begin{abstract}
Deep brain stimulation (DBS) of the anterior nucleus of the thalamus (ANT) is a promising treatment for patients with refractory epilepsy. However, therapy response varies and precise positioning of the DBS lead is potentially essential for maximizing therapeutic efficacy. We investigate if single-cell recordings acquired by microelectrode recordings can aid targeting of the ANT during surgery and hypothesize that the neuronal firing properties of the target region relate to clinical outcome. We prospectively included 10 refractory epilepsy patients and performed microelectrode recordings under general anesthesia to identify the change in neuronal signals when approaching and transecting the ANT. The neuronal firing properties of the target region, anatomical locations of microelectrode recordings and active contact positions of the DBS lead along the recorded trajectory were compared between responders and nonresponders to DBS.
\end{abstract}

$\S \S$ Corresponding author. 
We obtained 19 sets of recordings from 10 patients (five responders and five nonresponders). Amongst the 403 neurons detected, $365(90.6 \%)$ were classified as bursty. Entry into the ANT was characterized by an increase in firing rate while exit of the ANT was characterized by a decrease in firing rate. Comparing the trajectories of responders to nonresponders, we found differences neither in the neuronal firing properties themselves nor in their locations relative to the position of the active contact. Single-cell firing rate acquired by microelectrode recordings under general anesthesia can thus aid targeting of the ANT during surgery, but is not related to clinical outcome in DBS for patients with refractory epilepsy.

Keywords: Deep brain stimulation; anterior nucleus of the thalamus; epilepsy; microelectrode recordings.

\section{Introduction}

Deep brain stimulation (DBS) is a promising treatment for patients with refractory epilepsy who are ineligible for resective epilepsy surgery. After several case and pilot studies that showed a reduction of seizure frequency, ${ }^{1-6}$ the SANTE study was the first double-blinded, randomized, controlled trial for DBS of the anterior nucleus of the thalamus (ANT) in 110 refractory epilepsy patients. In this pivotal study, median seizure frequency reduced by $41 \%$ at 1-year follow-up and by $69 \%$ at 5 -year follow-up, with $16 \%$ of patients remaining seizure-free for at least 6 months. $^{7,8}$ Additional reports have confirmed the efficacy of DBS of the ANT for refractory epilepsy since the SANTE study. ${ }^{9-12}$ However, the therapeutic effect varies considerably among patients. While progressive improvement with neurostimulation is observed ${ }^{8}$ and tailoring of stimulation parameters can influence the clinical response, ${ }^{12}$ it remains unclear why certain patients respond to DBS of the ANT while others do not. Suboptimal targeting of the DBS lead likely plays a vital role in the observed differences in therapy response.

Single-cell recordings by microelectrodes during surgery may assist target identification and guide optimal placement of the DBS lead to improve clinical outcome. ${ }^{13}$ Given the recent technological advances in the field of DBS, ${ }^{14}$ DBS target identification and prediction of therapy response are areas where computational-based technologies could assist. ${ }^{15}$ This is illustrated by the development of commercially available software systems that map computer models and neurophysiological data on patient's MR images to guide DBS programming (https://clinicaltrials.gov/ct2/show/NCT03353688). Other systems even assist neurosurgical targeting by automatically detecting the entry and exit of the subthalamic nucleus in real-time using microelectrode recordings during DBS surgery for Parkinson's disease (https://clinicaltrials.gov/ct2/show/NCT03363724). As opposed to the subthalamic nucleus, ${ }^{13,16,17}$ little is known about the neuronal firing properties of the ANT and their relation to clinical outcome in DBS for patients with refractory epilepsy. ${ }^{18,19}$ The clinical utility of microelectrode recordings during DBS surgery for refractory epilepsy is therefore unclear. This is in part due to a limited number of subjects investigated and a variation of transventricular and extraventricular surgical trajectories used in clinical practice. Moreover, differences in neuronal firing properties of the target region have not been related to clinical outcome previously.

In this study, we investigate whether single-cell recordings acquired by microelectrode recordings along an extraventricular trajectory could aid targeting of the ANT during surgery and we hypothesize that the neuronal firing properties of the target region relate to therapy response in DBS for patients with refractory epilepsy.

\section{Methods}

\subsection{Patients}

Between 2011 and 2014, we prospectively included 10 consecutive refractory epilepsy patients with partial onset seizures scheduled for DBS surgery at Maastricht University Medical Center, the Netherlands. All patients failed to respond to trials of at least two reasonably tolerated and adequately chosen antiepileptic drug regimens. ${ }^{20,21}$ We only included patients who were considered ineligible for resective epilepsy surgery after general work-up by an expert panel (including video-EEG monitoring), or patients in whom previous epilepsy surgery or vagal nerve stimulation was not effective. Patients were excluded if they exhibited any of the following: psychiatric 
Table 1. Patient characteristics.

\begin{tabular}{|c|c|c|c|c|c|c|c|c|c|}
\hline Patient & $\begin{array}{l}\text { Therapy } \\
\text { response }\end{array}$ & Gender & $\begin{array}{l}\text { Age at } \\
\text { surgery } \\
\text { (years) }\end{array}$ & $\begin{array}{l}\text { Epilepsy } \\
\text { duration } \\
\text { (years) }\end{array}$ & Seizure type & Seizure focus & $\begin{array}{c}\text { Resective } \\
\text { surgery/VNS }\end{array}$ & $\begin{array}{l}\text { Baseline seizure } \\
\text { frequency/ } \\
\text { change to } \\
\text { baseline in \% } \\
\text { at 1-year FU }\end{array}$ & $\begin{array}{c}\text { Active } \\
\text { contact } \\
\text { at 1-year } \\
\text { follow-up } \\
\text { Left/Right }\end{array}$ \\
\hline 1 & $\mathrm{R}$ & Male & 41 & 20 & $\mathrm{CP}$ & $\begin{array}{l}\text { Right temporal } \\
\text { lobe }\end{array}$ & $\begin{array}{c}\text { Left temporal } \\
\text { lobe/No }\end{array}$ & 3/Seizure-free & $1 / 1$ \\
\hline 2 & $\mathrm{R}$ & Female & 35 & 33 & $\mathrm{SP}, \mathrm{CP}, \mathrm{TC}$ & $\begin{array}{l}\text { Bilateral } \\
\text { temporal lobe }\end{array}$ & No/ON & $7.7 /-87 \%$ & $0-1 / 0-1$ \\
\hline 3 & $\mathrm{R}$ & Male & 65 & 51 & $\mathrm{CP}$ & $\begin{array}{l}\text { Left frontal } \\
\text { lobe }\end{array}$ & $\begin{array}{l}\text { Left temporal } \\
\text { lobe/ } \\
\text { Removed }\end{array}$ & $23 /-52 \%$ & $0-1 / 0-1$ \\
\hline 4 & NR & Male & 46 & 23 & $\mathrm{CP}$ & $\begin{array}{l}\text { Right parietal } \\
\text { lobe }\end{array}$ & No/Removed & $4.7 /+28 \%$ & $1 / 1$ \\
\hline 5 & $\mathrm{R}$ & Male & 48 & 39 & $\mathrm{SP}, \mathrm{CP}$ & $\begin{array}{l}\text { Bilateral } \\
\text { temporal lobe }\end{array}$ & No/No & $0.5 /$ Seizure-free & $1 / 1$ \\
\hline 6 & NR & Male & 36 & 13 & $\mathrm{CP}, \mathrm{TC}$ & $\begin{array}{l}\text { Left temporal } \\
\text { lobe }\end{array}$ & $\mathrm{No} / \mathrm{ON}$ & $7.7 /-35 \%$ & $1 / 1$ \\
\hline 7 & $\mathrm{R}$ & Female & 30 & 12 & $\mathrm{SP}, \mathrm{CP}$ & $\begin{array}{l}\text { Right } \\
\text { temporal lobe }\end{array}$ & $\begin{array}{l}\text { Left temporal } \\
\text { lobe/ON }\end{array}$ & 10/Seizure-free & $1 / 1$ \\
\hline 8 & NR & Male & 40 & 30 & $\mathrm{CP}$ & Left frontal lobe & $\mathrm{No} / \mathrm{No}$ & $18.5 /-42 \%$ & $1 / 1$ \\
\hline 9 & NR & Male & 38 & 29 & $\mathrm{SP}, \mathrm{CP}, \mathrm{TC}$ & $\begin{array}{r}\text { Multifocal } \\
\text { epilepsy }\end{array}$ & $\mathrm{No} / \mathrm{ON}$ & $7.5 /+20 \%$ & $1 / 1$ \\
\hline 10 & NR & Male & 40 & 29 & $\mathrm{~T}, \mathrm{CP}, \mathrm{TC}$ & $\begin{array}{l}\text { Right parietal } \\
\text { lobe }\end{array}$ & No/Removed & $268 /+34 \%$ & $1 / 1$ \\
\hline
\end{tabular}

Notes: Abbreviations are: $\mathrm{R}=$ responder; $\mathrm{NR}=$ nonresponder; $\mathrm{SP}=$ simple partial; $\mathrm{CP}=$ complex partial; $\mathrm{T}=$ tonic; $\mathrm{TC}$, tonic--clonic; $\mathrm{FU}=$ follow-up; and $\mathrm{VNS}=$ vagal nerve stimulation.

co-morbidities such as severe depression or psychosis, severe pulmonary disease, uncontrolled hypertension and blood coagulation disorders. Patient characteristics are presented in Table 1.

\subsection{Ethics}

The study was approved by the Medical Ethical Testing Committee of Maastricht University Medical Center (ID: METC 14-4-126).

\subsection{Imaging}

As part of standard clinical practice, all subjects had a pre-operative 3-T MRI (Philips, Eindhoven, The Netherlands) or 1.5-T MRI in case of an implanted vagal nerve stimulator for stereotactic planning of the electrode trajectory. The sequences used were a 3D T1 with gadolinium, axial T2 and a T1 inversion recovery. Post-operatively, a CT or a 1.5-T T1 MRI was performed to localize the DBS lead.

\subsection{Surgical procedures}

Surgical procedures were performed under general anesthesia with remifentanil and propofol. A Leksell stereotactic frame (Model G, Elekta Instrument, Stockholm, Sweden) was mounted onto the skull of the patient. Subsequently, a per-operative stereotactic CT scan of the head with stereotactic frame was acquired and fused with the pre-operative MR images using Framelink software (Medtronic, Fridley, USA). The planned target was the center of the ANT. We planned an extraventricular approach to target, typically transecting the internal capsule (IC) and other thalamic nuclei before entering the ANT. Along this trajectory, we performed microelectrode recordings (MicroMacroElectrode, ISIS MER, Inomed, Emmendingen, Germany) to identify the neuronal signals when approaching and transecting the target region. For more details on our stereotactic surgical procedures, we refer to previous publications. ${ }^{22,23}$

\subsection{Microelectrode recordings}

Single-cell potentials were recorded at a sampling frequency of $20 \mathrm{kHz}$ or $25 \mathrm{kHz}$, with a bandpass filter of $160-5000 \mathrm{~Hz}$, for at least $30 \mathrm{~s}$ at each step starting with 1-mm intervals from $10 \mathrm{~mm}$ above target and $0.5-\mathrm{mm}$ intervals from $5 \mathrm{~mm}$ above target until 


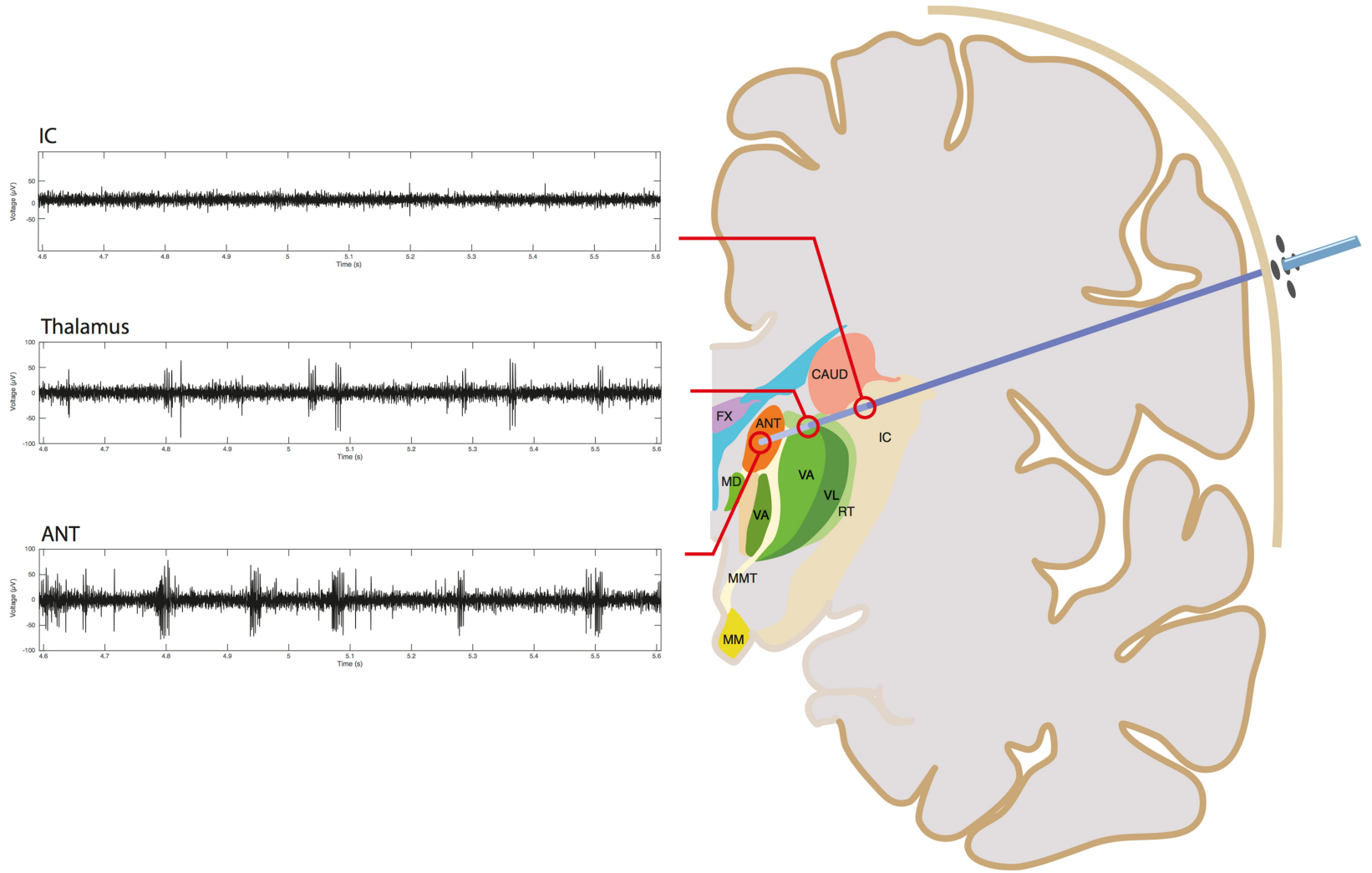

Fig. 1. Schematic representation of an extraventricular trajectory to the ANT with representative microelectrode recording signals of internal capsule, thalamus and ANT region at $-10 \mathrm{~mm},-5 \mathrm{~mm}$ and at target, respectively. Note that in the IC almost no spikes are present, in the thalamus a typical bursty signal and in the ANT a bursty signal with a high firing rate are observed. Abbreviations: ANT, anterior nucleus of thalamus; MM, mammillary bodies; IC, internal capsule; MMT, mammillothalamic tract; CAUD, caudate nucleus; FX, fornix; RT, reticular tract; VL, ventrolateral nucleus of thalamus; VA, ventral anterior nucleus of thalamus; and MD, mediodorsal nucleus of thalamus.

maximally $5 \mathrm{~mm}$ below target (Fig. 1). The macrocontact was the reference contact for microelectrode recordings at the microtip. In only one patient, the lateral trajectory was chosen in one hemisphere as the central trajectory did not show typical spiking activity. After microelectrode recording, the final DBS lead (Model 3389, Medtronic, Fridley, USA) was implanted along the same trajectory with contact 1 (contact 0 is the most distal contact) typically situated at target. Subsequently, the leads were connected to an internal pulse generator (Activa PC, Medtronic, Fridley, USA). To relate neuronal firing properties to therapy response, we analyzed the microelectrode recording trajectories used for DBS lead implantation.

The anatomical locations of the microelectrode recordings were verified by fusing pre-operative
MR and post-operative CT images. Landmarks for identifying the boundaries of the ANT on preoperative 3-T MRI were the mammillothalamic tract, external medullary lamina, third ventricle and lateral ventricle. The microelectrode recording trajectory was reconstructed using Framelink software (Stealthstation, Medtronic, Fridley, USA) via the coordinates of planned target and skull entry point. Along this trajectory, two observers (Yasin Temel, Rob P. W. Rouhl) manually confirmed and reached consensus for the location of microelectrode recording at every depth relative to target to ensure the recording was taken from the $\mathrm{IC}$, thalamus or ANT. The mean depths of entry into the thalamus, ANT and exit out of the ANT region were subsequently calculated. The distance of the active contact along the implantation trajectory was derived from the 
final position of contact 0 relative to target during surgery, considering a 2-mm spacing between the centers of successive contacts for the Medtronic 3389 lead model.

\subsection{Deep brain stimulation}

The neurosurgeon (Yasin Temel) evaluated the location of the DBS lead for minor post-surgical movement on fused pre-operative and post-operative images. Stimulation of the contact closest to the center of the ANT started 5-8 weeks after surgery. Primary stimulation parameters were identical to those in the SANTE study ${ }^{7,8}$ and consisted of monopolar stimulation with a frequency of $145 \mathrm{~Hz}$, a pulse width of $90 \mu \mathrm{s}$, an intensity of $5 \mathrm{~V}$ and cycling mode of $1 \mathrm{~min}$ on and $5 \mathrm{~min}$ off. Stimulation parameters were tailored at the discretion of the treating neurologists (Louis Wagner, Albert J. Colon) during regular follow-up moments, which are generally performed by adapting the current amplitude, pulse width and/or frequency to control the volume of tissue activation. ${ }^{24}$ After 1 year, the treating neurologist assessed the clinical response to DBS therapy. Responders were defined as patients exhibiting a seizure frequency reduction of $\geq 50 \%$ compared to baseline and nonresponders as patients exhibiting a seizure frequency reduction of $<50 \%$ compared to baseline. We classified five patients as responders and five patients as nonresponders to DBS. Patient characteristics, seizure frequency at baseline and active contacts are presented in Table 1.

\subsection{Data analysis}

We obtained 19 sets of recordings from nine bilateral and one unilateral microelectrode recording trajectories from 10 patients. One patient only had microelectrode recording on the left hemisphere to reduce the risk for intracranial bleeding accompanied with a dense collection of vessels in the target region at the right hemisphere. Microelectrode recordings were processed with MATLAB and Statistics Toolbox R2012a (Mathworks, Natick, USA). First, the recorded signal was bandpass filtered $(350-5000 \mathrm{~Hz})$ with the filtfilt command to isolate the action potential component of the signal. Mechanical artifacts in the microelectrode recordings were automatically identified. ${ }^{17}$ Signals with artifacts were not included for further analysis. Spikes were detected from the filtered data using an envelope noise-detection method. ${ }^{25}$ The spikes were then sorted into single neuronal units using Haar wavelet coefficients ${ }^{26}$ as input features for an expectation-maximization clustering algorithm. Next, we classified the firing pattern of every neuron based on their discharge density histogram. ${ }^{27}$ In short, the spike train was first binned using the mean interspike interval as the bin width. The histogram of the number of spikes per interval was statistically compared with the Poisson, normal and bimodal distributions to determine if the firing pattern was random, regular or bursty. For each neuron, we then calculated the mean firing rate (MFR) and, for bursty neurons, the mean burst rate (MBR) and MFR within bursts (MFRib). Microelectrode recordings with an insufficient number of spikes for classification $(<100$ spikes or $<10 \mathrm{~s}$ of spike activity) were classified as unknown.

The firing characteristics for each recording were summarized by mapping them onto the corresponding microelectrode recording location, labeled as distance relative to target, where location 0 corresponds to the planned target. The distributions of each of the three firing patterns along the trajectory were constructed by calculating the number of recorded cells from all patient recordings that showed regular, random, bursty or unknown firing patterns at a certain depth. To facilitate comparisons between different sets of recordings from diverse patients, the mean firing and burst rates along each trajectory were first normalized by dividing them by the maximum firing or burst rate recorded along the trajectory in a specific patient. Firing characteristics were then averaged for each recording depth across all recordings at that depth for the total population of responders and nonresponders. Curves were then smoothed using a three-point moving average.

\subsection{Statistical analysis}

Group comparisons of anatomical locations of microelectrode recordings were conducted using the twosample Kolmogorov-Smirnov test on the empirical distribution functions along the trajectory. For the percentage of bursty cells, MFR, MBR and MFR within bursts, a linear mixed model was used to test whether these firing characteristics varied with the patient group and/or depth to target and any interaction between these two factors. An unpaired 
Student's t-test was used to compare the distance between the active contact and the location of the peaks in MFR, MBR and MFR within bursts between responders and nonresponders. Firing characteristics and distances to target are presented as mean \pm standard error (SE), unless otherwise stated. All statistical tests were performed in MATLAB and a $p$-value $<0.05$ was considered statistically significant.

\section{Results}

\subsection{Neuronal firing properties}

The electrophysiological characteristics of all singlecell recordings are summarized in Table 2. Amongst the 403 neurons detected, $365(90.6 \%)$ were classified as bursty with a mean \pm SE number of spikes per burst of $3.6 \pm 0.1$, a burst duration of $9.6 \pm 0.3 \mathrm{~ms}$ and an interburst interval of $890.8 \pm 47 \mathrm{~ms}$. Based on the anatomical verification of the planned trajectory on pre-operative MR images, the mean point of entry into the thalamus was at $-7.5 \pm 0.5 \mathrm{~mm}$ relative to target, entry into the ANT at $-3.8 \pm 0.2 \mathrm{~mm}$ and the mean exit out of ANT was at $+2.3 \pm 0.4 \mathrm{~mm}$.
Table 2. Electrophysiological characteristics of single cell recordings in mean \pm standard error across all depths from all the subjects.

\begin{tabular}{lr}
\hline Electrophysiological characteristic & Mean $\pm \mathrm{SE}$ \\
\hline Spike rate $^{\mathrm{a}}(\mathrm{Hz})$ & $20.9 \pm 0.9$ \\
Spike amplitude $^{\mathrm{a}}(\mu \mathrm{V})$ & $55.4 \pm 0.2$ \\
Burst rate $^{\mathrm{b}}(\mathrm{Hz})$ & $1.6 \pm 0.1$ \\
Spike rate within bursts $^{\mathrm{b}}(\mathrm{Hz})$ & $447.9 \pm 5.7$ \\
Number of spikes per burst $^{\mathrm{b}}$ & $3.6 \pm 0.1$ \\
Burst duration $^{\mathrm{b}}(\mathrm{ms})$ & $9.6 \pm 0.3$ \\
Interburst interval $^{\mathrm{b}}(\mathrm{ms})$ & $890.8 \pm 47$ \\
\hline
\end{tabular}

Notes: ${ }^{\mathrm{a}}$ Averaged over $N=403$ neurons. ${ }^{\mathrm{b}}$ Averaged over $N=365$ bursty neurons.

A typical thalamic bursty firing pattern was seen when entering the thalamus and ANT (Figs. 1 and 2). Considerably lower numbers of neurons were detected above $-6 \mathrm{~mm}$ relative to target in the region of the $\mathrm{IC}$ and below $-2 \mathrm{~mm}$ after exiting the ANT (Fig. 2). Entry into the ANT was characterized by an increase in the MFR while exit from ANT was characterized by a decrease in the MFR, MBR and MFR within bursts (Fig. 3).

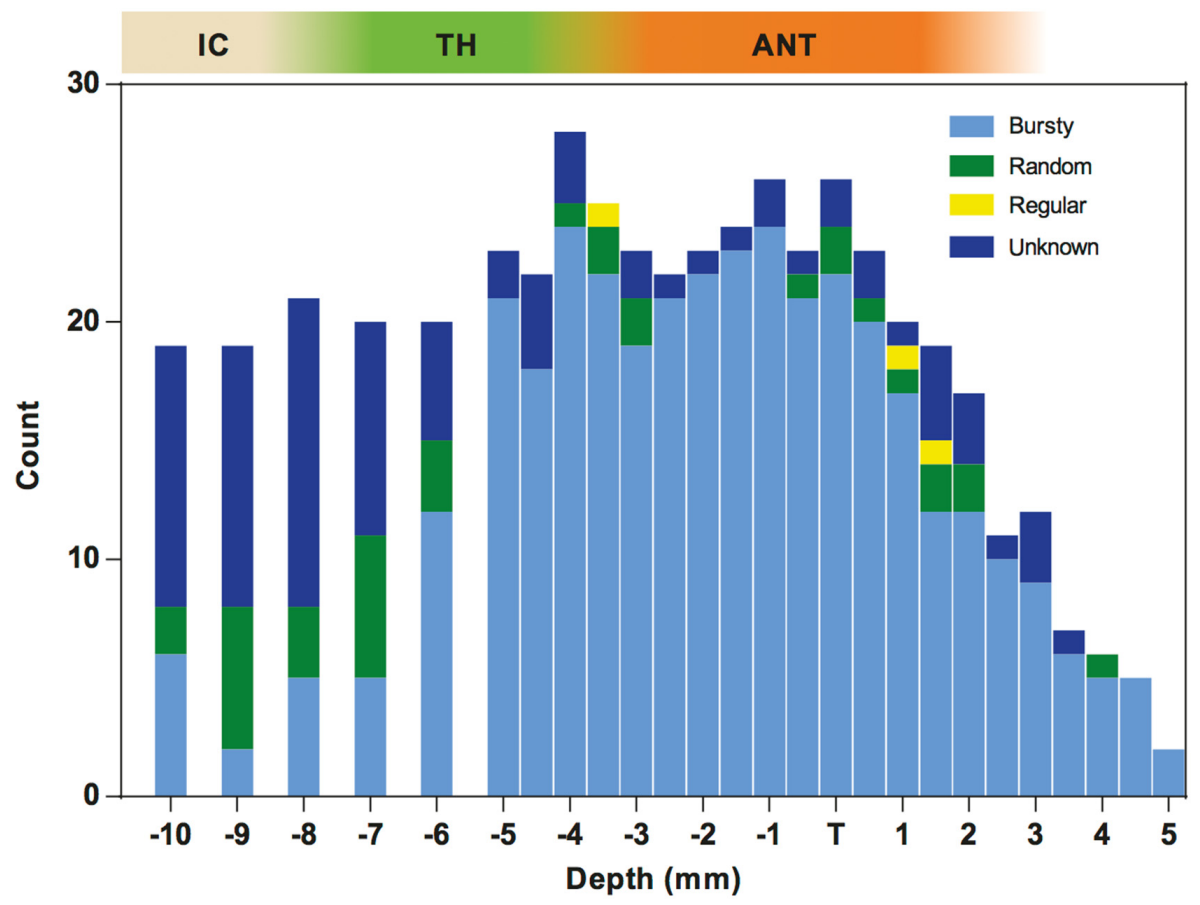

Fig. 2. Histogram of the total neuron count and distribution of different cell types by their firing characteristics (bursty, regular, random or unknown) along the trajectory. Note the increase of proportion of bursty cells when approaching the thalamus and ANT. Here IC = internal capsule; $\mathrm{TH}=$ thalamus; and $\mathrm{ANT}=$ anterior nucleus of the thalamus. 


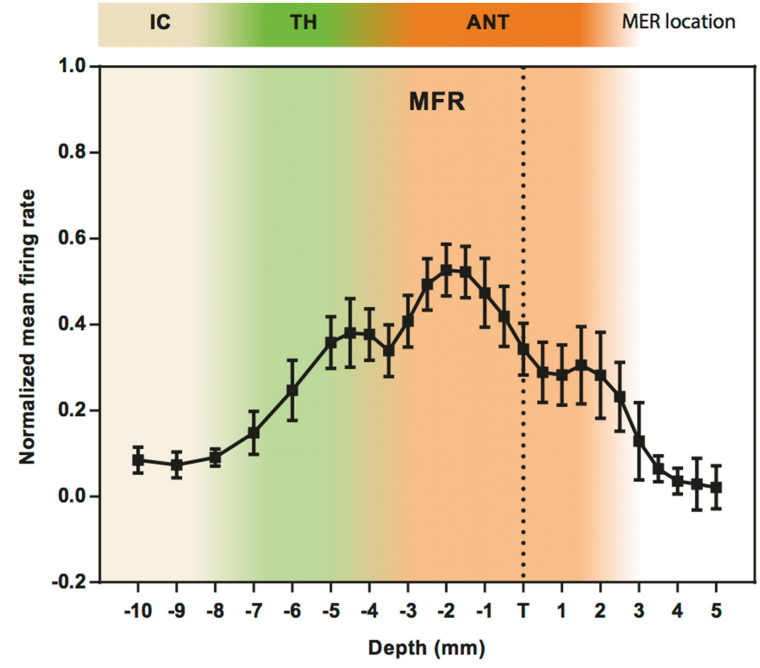

(a)

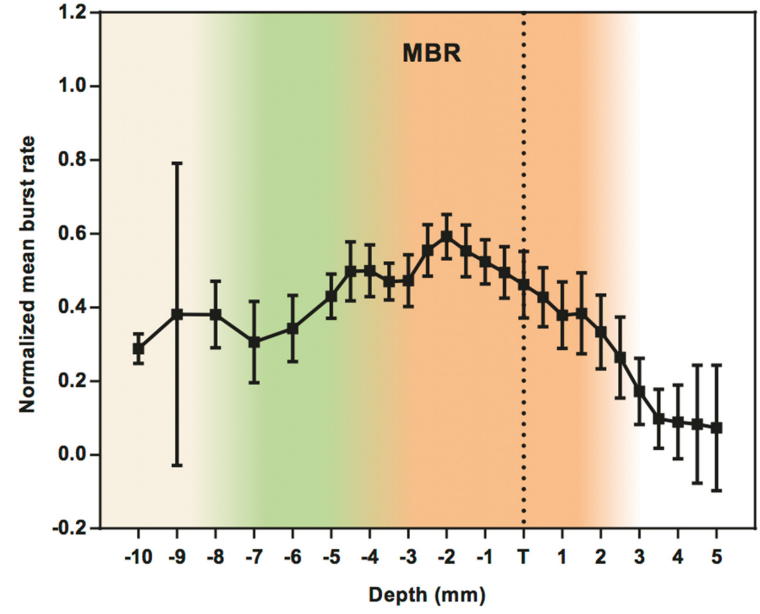

(b)

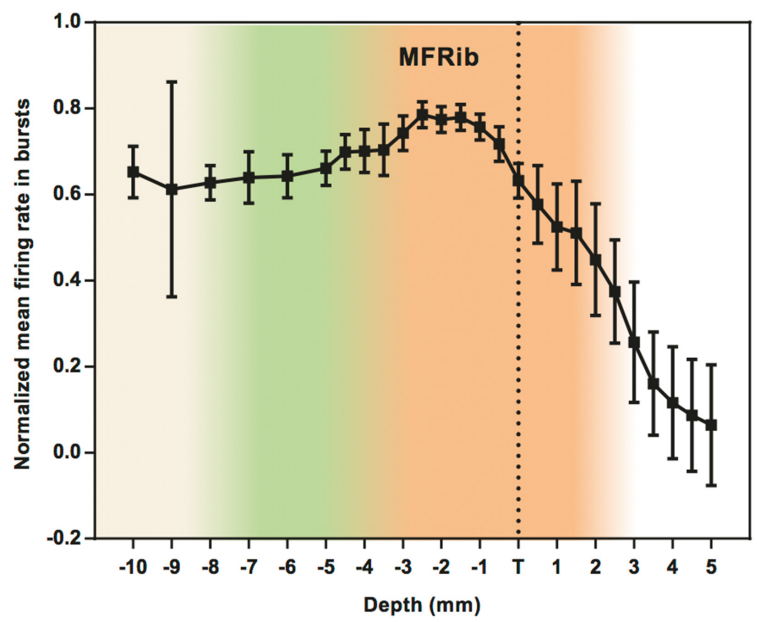

(c)

Fig. 3. Neuronal firing properties along the trajectory for all subjects. (a) Normalized MFR, (b) normalized MBR and (c) normalized MFRib. Note the increase in MFR when approaching the target and the decrease when crossing the target. Error bars represent standard errors of the mean.

The MFR $[F(23,437)=8.64, p<0.0001]$, MBR $[F(23,330)=5.93, p<0.001]$, and MFR within bursts $[F(23,329)=14.55, p<0.0001]$ all significantly changed with depth along the trajectory. Moreover, MFR, MBR and MFR within bursts consistently reached a peak around $-2 \mathrm{~mm}$ to target. Both in the total population (Fig. 3) and in an individual subject (Fig. 4), we identified a profile of an increase in firing rate when entering the thalamus, followed by a zone without spikes and a subsequent increase in firing rate when entering and decrease when exiting the ANT. After review of the individual patient data, we found that 15 out of 19 trajectories fulfilled this profile with an approximate firing rate range of $10-60 \mathrm{~Hz}$ in ANT recordings. Other firing characteristics such as spike amplitude, spikes per burst, burst duration and interburst duration did not markedly change along the trajectory and were not further analyzed.

\subsection{Responders versus nonresponders}

There was no significant difference between the distributions of percentage of bursty cells for responders 


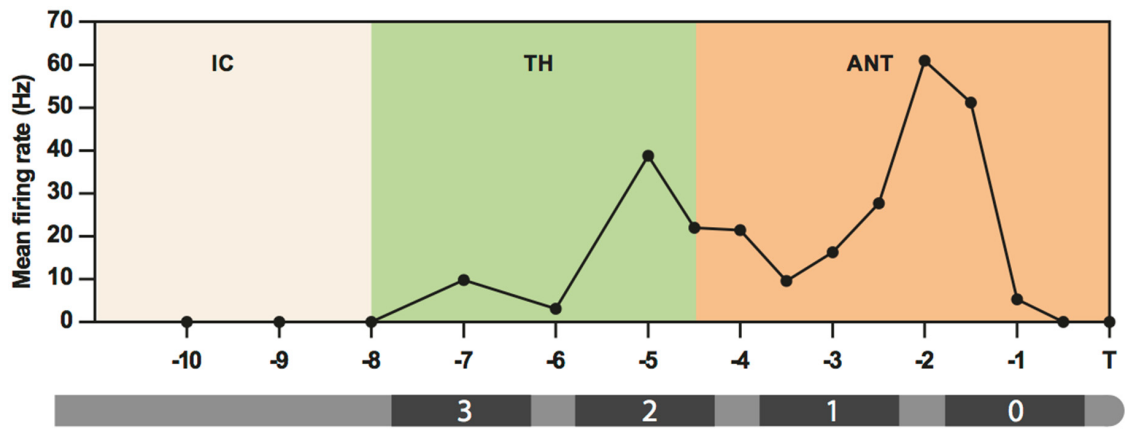

Depth (mm)

Fig. 4. Individual subject example (case 2: right hemisphere) of the mean firing rate along the recorded trajectory to target and a schematic representation of DBS lead placement. Note the increase in mean firing rate when entering and decrease when exiting the ANT. Following microelectrode recordings, the DBS lead was implanted along the same trajectory and the center of contact 0 was positioned at $-1 \mathrm{~mm}$ to target.

(a)

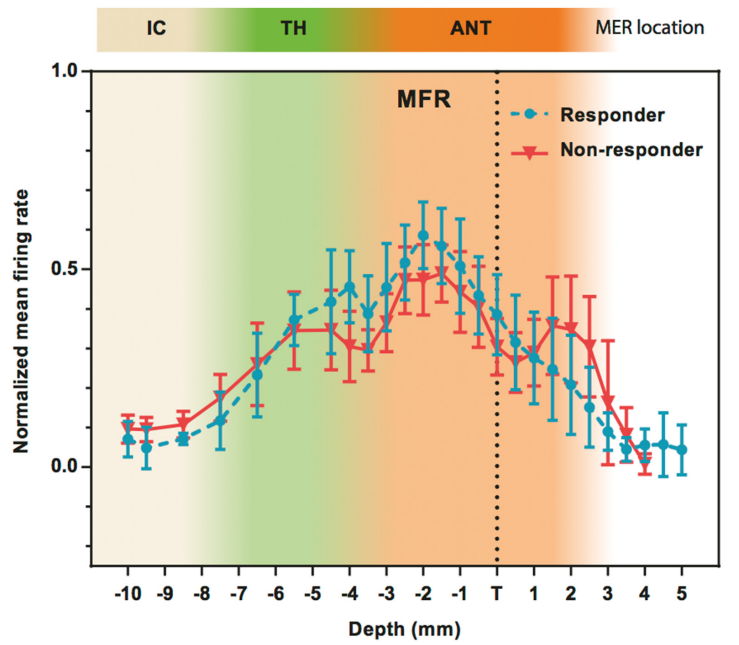

(b)

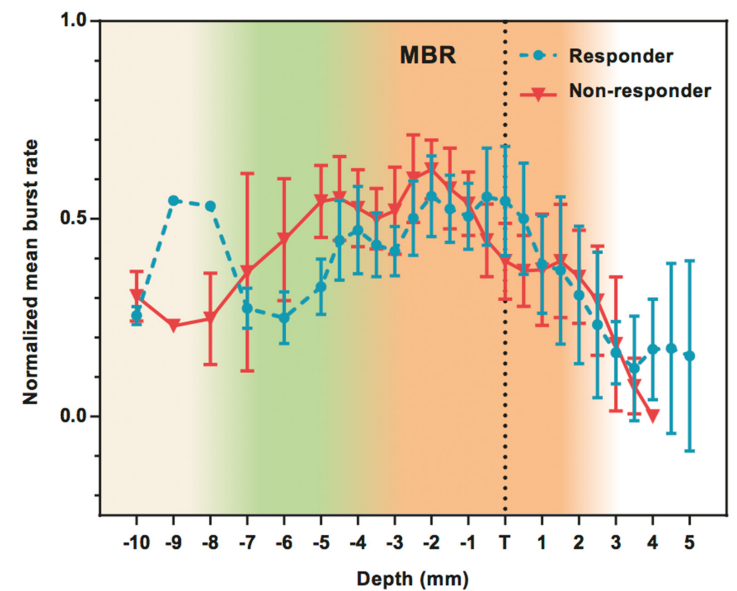

(c)

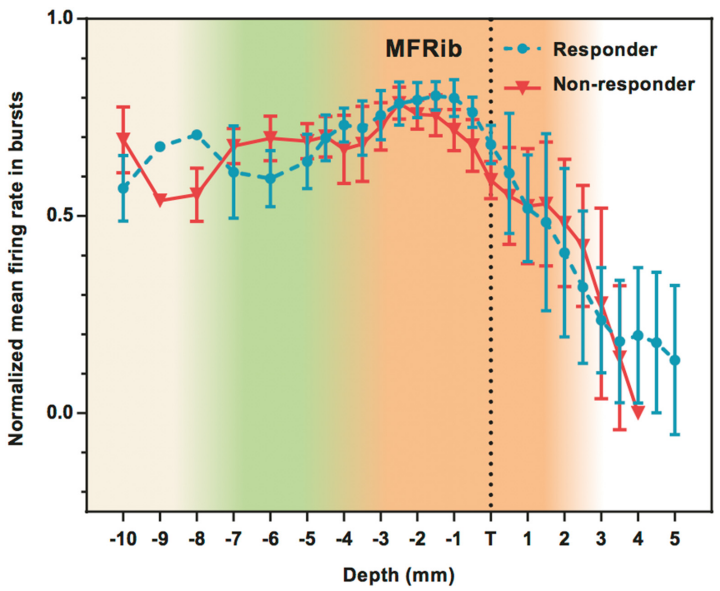

Fig. 5. (Color online) Neuronal firing properties along the trajectory for responders (blue dashed lines) and nonresponders (red solid lines). (a) Normalized MFR, (b) normalized MBR and (c) normalized MFRib. Error bars represent standard errors of the mean. 
and nonresponders. Further investigation of distributions of MFR, MBR and MFR within bursts revealed no significant difference along the trajectory (Fig. 5) between the two groups. There were no interaction effects between depth and group. Anatomical locations of microelectrode recording did not differ between responders and nonresponders, since the probability of a recording being taken from the internal capsule, thalamus or ANT along the different depths of the trajectory did not significantly differ. We additionally evaluated if active contact placement near the peak of the firing characteristics could be related to clinical response. However, we did not find a difference in the distances of the active contact to the peak of MFR, MBR or MFR within bursts between responders and nonresponders (means ranged from $0.7 \mathrm{~mm}$ to $2.4 \mathrm{~mm}$ ). To evaluate if the probable location of the epileptogenic zone relates to the nature of the neuronal signals along the trajectory, we compared the neuronal firing properties between patients with temporal and extra-temporal onset of seizures (Table 1), but no differences were found.

\section{Discussion}

Single-cell recordings acquired by microelectrode recordings during DBS surgery were obtained from 10 patients with refractory epilepsy. A total of 19 extraventricular microelectrode recording trajectories were used to analyze clinically relevant parameters for defining the target region and were subsequently compared between responders and nonresponders to DBS. We found an incremental increase in firing rate when entering the ANT and a decrease in firing rate when exiting the ANT. Comparing the trajectories of responders to nonresponders, we found differences in neither the neuronal firing properties themselves nor their locations relative to the position of the active contact. Singlecell firing rate detected by microelectrode recording under general anesthesia can aid in targeting the ANT during surgery, but is not related to therapy response in DBS for patients with refractory epilepsy. Other factors such as patient characteristics (e.g. location of seizure onset and epilepsy etiology), location, duration and parameters of stimulation likely play a role in therapy response.

Single-cell recordings could be implemented in machine learning models for computational tools that assist the neurosurgical team with DBS target identification. This model can, in theory, be built by taking a set of inputs (e.g. features related to the patient) and mapping them onto the desired output (e.g. location of the ANT or therapy response to DBS). The performance of the model and its engineering potential depend on the selection of relevant and discriminating features. ${ }^{28}$ In this study, we therefore conducted a thorough exploration of microelectrode recording data to identify electrophysiological features that may correlate with the location of the ANT and/or relate to therapy response to DBS. Explored features include the neuronal firing pattern (regular, bursty or random), mean firing rate, burst rate, firing rate within bursts, burst duration, interburst duration, spikes per burst and spike amplitude. Amongst these features, we found that only the firing pattern and mean firing rates varied in a systematic manner along the trajectory. As such, we focused our analyses on these parameters and compared these between responders and nonresponders to DBS. Our results show that a clear peak in the firing rate precedes the intended DBS target defined on pre-operative MR images. The simplicity of this feature, which is expected not to be computationally intensive, means that localization of the ANT during surgery may be possible via real-time analysis of firing rate during DBS surgery. Subsequently, the trajectory for definitive lead implantation can be chosen and lead implantation can be guided for optimal placement of the DBS electrode contacts relative to the neuronal signals of the ANT. The clinical utility of this technique would be to more accurately place the DBS electrode within the anatomic and electrophysiological defined ANT. Although we found a change in firing rate along the trajectory, this feature did not relate to therapy response. This is possibly due to the dimensions of the electrode and coarser effects of DBS compared to the distribution of neuronal signals recorded with microelectrode recordings. Considering the intensity of stimulation is generally around $5 \mathrm{~V}$, we estimate that the volume of tissue activation will cover the ANT and peak in firing rate in both responders and nonresponders. A more specific target localization, using computational tools that combine electrophysiological data, MR images and volume of tissue activation models, could enable more focal stimulation to consume less battery, prevent side effects and expand our 
knowledge on the clinical importance of the ANT as an anatomic and electrophysiological target in DBS for epilepsy.

Hodaie et $a l .{ }^{18}$ first described the electrophysiological properties of the human ANT during DBS surgery. In contrast to our extraventricular approach under general anesthesia, the authors used a transventricular trajectory to the ANT and performed microelectrode recordings under local anesthesia in five subjects with intractable epilepsy. They found bursting activity in the ANT and characterized most bursts as low-threshold calcium spike (LTS) mediated bursts, which are generally only observed during sleep. Although we did not specifically analyze LTS bursts, our burst characteristics (number of spikes per burst and burst duration) obtained under general anesthesia look similar (Table 2) and do not markedly change along the trajectory. LTS bursts may thus be due to an altered electrophysiological state in epilepsy or a result of long-term anticonvulsant use. As there were no recordings in normal control subjects and no concurrent EEG recordings were performed, the authors note that it cannot be ruled out that bursting activity is normal in awake patients. ${ }^{29}$ LTS bursts were however not specific to the ANT, as they were additionally found in the nucleus cucularis and dorsal dorsomedian nucleus of the thalamus. Moreover, the percentage of LTS bursts found was similar at different depths along the trajectory since they were frequently found after exiting the estimated ventral border of the ANT. Although the authors describe an interesting finding for a potential role of thalamic bursting in facilitating seizure propagation, the lack of specificity and minimal change in LTS bursts along the trajectory might preclude its use to target the ANT.

Along an extraventricular trajectory, we report a change in firing characteristics when entering and exiting the ANT. The parameter that most prominently depicted the ANT was the firing rate, which increased until it reached a peak around $-2 \mathrm{~mm}$ to target and subsequently decreased. A change in firing rate along an extraventricular trajectory to the ANT was previously reported in two subjects by Möttönen et al. ${ }^{19}$ The authors describe a zone without spikes at the lateral aspect of the ANT and attributed this to white matter lamina between the ANT and other thalamic subnuclei as defined by 3 -T MRI. Our results support this finding, as we see a decrease in mean firing or spike rate before entering the lateral ANT (Figs. 3 and 4), which we consider is most likely caused by passing through the medullary lamina of the thalamus. Using five transventricular and five extraventricular trajectories from five subjects, the same group investigated the firing characteristics of different nuclear groups of the thalamus. ${ }^{30}$ They found that the spike frequency in recordings most likely taken from the ANT were significantly lower than the recordings taken from the ventral anterior nucleus (VA) with morphologically similar bursts. In contrast, we found a peak in mean firing rate at $-2 \mathrm{~mm}$ to target from the recordings most likely taken from the ANT. Although we did not compare the firing rate between the ANT and VA, our findings suggest a higher firing rate in the ANT (within the approximate range of $10-60 \mathrm{~Hz}$ ) than in other thalamic nuclei. While we cannot exclude that some of our recordings might have been taken from the VA, the aim of our study was not to distinguish between firing characteristics of different thalamic nuclei but to describe the change in firing characteristics when approaching and transecting the ANT region using an extraventricular approach. The difference in firing rates found between Möttönen et al. and our study can possibly be explained by details of the surgical trajectory, analysis of spike rate, patient characteristics or used anesthesia. Although in the SANTE study a transventricular surgical trajectory was chosen $^{7}$ and is commonly advised for targeting the $\mathrm{ANT}^{31}$ we have, like others, ${ }^{32}$ consistently planned an extraventricular trajectory, avoiding the choroid plexus, thalamostriatal veins and branches of the internal cerebral veins to reduce the risk for intracranial hemorrhage associated with passing through the lateral ventricle.

\subsection{Limitations}

This study is, inherent to a microelectrode recording study, limited by the anatomical verification of recordings. Due to the small size and low intrinsic MR signal and contrast of the intrathalamic nuclei, it is challenging to distinguish between the different thalamic subnuclei with conventional MRI sequences. We therefore used well-described borders of the ANT (such as the mammillothalamic tract and external medullary lamina) to reach consensus 
between two observers if a patient-specific recording was taken from the IC, thalamus or ANT. Future studies projecting microelectrode recording data onto images obtained via ultra-high-field MR in conjunction with optimized sequences for visualization of the intrathalamic nuclei ${ }^{33}$ will likely advance classification of the firing characteristics of different nuclear groups within the thalamus and possibly even within the ANT.

While we present the largest set of single-cell recordings from epilepsy patients who were treated with DBS to date, this study remains underpowered by the low number of subjects and group sizes. We found no difference in neuronal firing properties between responders and nonresponders to DBS and between patients with temporal and nontemporal lobe localizations of seizures. While analysis of larger cohorts is required, comparable neuronal firing properties of the ANT under general anesthesia in a heterogeneous epilepsy patient population might be an advantage for reliably targeting the ANT during DBS surgery using microelectrode recordings.

\section{Conclusion}

Single-cell firing rate acquired by microelectrode recordings under general anesthesia can aid targeting of the ANT during surgery, but is not related to clinical outcome in DBS for patients with refractory epilepsy.

\section{Acknowledgments}

We would like to thank Bethany R. Isaacs for her English corrections and Geertjan van Zonneveld for his artistic contribution to the figures in this paper. This research did not receive any specific grant from funding agencies in the public, commercial or notfor-profit sectors. Frédéric L. W. V. J. Schaper and Yan Zhao contributed equally to this work. Similarly, Vivianne H. J. M. Van Kranen-Mastenbroek and Rob P. W. Rouhl contributed equally to this work.

\section{References}

1. I. S. Cooper, A. R. Upton and I. Amin, Reversibility of chronic neurologic deficits: Some effects of electrical stimulation of the thalamus and internal capsule in man, Appl. Neurophysiol. 43 (1980) 244-258.
2. M. Hodaie, R. A. Wennberg, J. O. Dostrovsky and A. M. Lozano, Chronic anterior thalamus stimulation for intractable epilepsy, Epilepsia 43 (2002) 603-608.

3. J. F. Kerrigan et al., Electrical stimulation of the anterior nucleus of the thalamus for the treatment of intractable epilepsy, Epilepsia 45 (2004) 346-354.

4. A. R. Upton et al., Evoked metabolic responses in the limbic-striate system produced by stimulation of anterior thalamic nucleus in man, Pacing Clin. Electrophysiol. 10 (1987) 217-225.

5. D. M. Andrade et al., Long-term follow-up of patients with thalamic deep brain stimulation for epilepsy, Neurology 66 (2006) 1571-1573.

6. S.-N. Lim et al., Electrical stimulation of the anterior nucleus of the thalamus for intractable epilepsy: A long-term follow-up study, Epilepsia 48 (2007) 342347.

7. R. Fisher et al., Electrical stimulation of the anterior nucleus of thalamus for treatment of refractory epilepsy, Epilepsia 51 (2010) 899-908.

8. V. Salanova et al., Long-term efficacy and safety of thalamic stimulation for drug-resistant partial epilepsy, Neurology 84 (2015) 1017-1025.

9. K. J. Lee, Y.-M. Shon and C. B. Cho, Long-term outcome of anterior thalamic nucleus stimulation for intractable epilepsy, Stereotact. Funct. Neurosurg. 90 (2012) 379-385.

10. V. Krishna et al., Anterior nucleus deep brain stimulation for refractory epilepsy: Insights into patterns of seizure control and efficacious target, Neurosurgery 78 (2016) 802-811.

11. M. Piacentino et al., Anterior thalamic nucleus deep brain stimulation (DBS) for drug-resistant complex partial seizures (CPS) with or without generalization: Long-term evaluation and predictive outcome, Acta Neurochir. (Wien) 157 (2015) 1525-1532.

12. K. Lehtimäki et al., Outcome based definition of the anterior thalamic deep brain stimulation target in refractory epilepsy, Brain Stimul. 9 (2016) 268275 .

13. L. J. Bour et al., Long-term experience with intraoperative microrecording during DBS neurosurgery in STN and GPi, Acta Neurochir. (Wien) 152 (2010) 2069-2077.

14. C. Ineichen et al., A critical reflection on the technological development of deep brain stimulation (DBS), Front. Hum. Neurosci. 8 (2014) 730.

15. R. R. Shamir et al., Machine learning approach to optimizing combined stimulation and medication therapies for Parkinson's disease, Brain Stimul. 8 (2015) 1025-1032.

16. E. Kocabicak et al., Is there still need for microelectrode recording now the subthalamic nucleus can be well visualized with high field and ultrahigh MR imaging? Front. Integr. Neurosci. 9 (2015) 46.

17. A. Moran et al., Subthalamic nucleus functional organization revealed by Parkinsonian neuronal 
oscillations and synchrony, Brain 131 (2008) 33953409.

18. M. Hodaie et al., Bursting activity of neurons in the human anterior thalamic nucleus, Brain Res. 1115(1) (2006) 1-8.

19. T. Möttönen et al., Defining the anterior nucleus of the thalamus (ANT) as a deep brain stimulation target in refractory epilepsy: Delineation using $3 \mathrm{~T}$ MRI and intraoperative microelectrode recording, $\mathrm{Neu}$ roimage Clin. 7 (2015) 823-829.

20. P. Kwan and M. J. Brodie, Early identification of refractory epilepsy, N. Engl. J. Med. 342 (2000) 314319 .

21. P. Kwan et al., Definition of drug resistant epilepsy: Consensus proposal by the ad hoc task force of the ILAE commission on therapeutic strategies, Epilepsia 51 (2009) 1069-1077.

22. M. L. F. Janssen et al., Subthalamic nucleus highfrequency stimulation for advanced Parkinson's disease: Motor and neuropsychological outcome after 10 years, Stereotact. Funct. Neurosurg. 92 (2014) 381387.

23. E. Kocabicak and Y. Temel, Deep brain stimulation of the subthalamic nucleus in Parkinson's disease: Surgical technique, tips, tricks and complications, Clin. Neurol. Neurosurg. 115 (2013) 23182323.

24. C. R. Butson et al., Patient-specific analysis of the volume of tissue activated during deep brain stimulation, Neuroimage 34 (2007) 661-670.
25. K. Dolan et al., Automatic noise-level detection for extra-cellular micro-electrode recordings, Med. Biol. Eng. Comput. 47 (2009) 791-800.

26. J. C. Letelier and P. P. Weber, Spike sorting based on discrete wavelet transform coefficients, J. Neurosci. Methods 101 (2000) 93-106.

27. Y. Kaneoke and J. L. Vitek, Burst and oscillation as disparate neuronal properties, J. Neurosci. Methods 68 (1996) 211-223.

28. A. L. Blum and P. Langley, Selection of relevant features and examples in machine learning, Artif. Intell. 97 (1997) 245-271.

29. S. Ohara et al., Spontaneous low threshold spike bursting in awake humans is different in different lateral thalamic nuclei, Exp. Brain Res. 180 (2007) 281-288.

30. T. Möttönen et al., The correlation between intraoperative microelectrode recording and 3-tesla MRI in patients undergoing ANT-DBS for refractory epilepsy, Stereotact. Funct. Neurosurg. 94 (2016) 8692.

31. A. Cukiert and K. Lehtimäki, Deep brain stimulation targeting in refractory epilepsy, Epilepsia 58 (2017) $80-84$.

32. J. J. Van Gompel et al., Anterior nuclear deep brain stimulation guided by concordant hippocampal recording, Neurosurg. Focus 38(6) (2015) E9.

33. T. Tourdias et al., Visualization of intrathalamic nuclei with optimized white-matter-nulled MPRAGE at 7T, Neuroimage 84 (2014) 534-545. 